УДК 538.9

\title{
ВЛИЯНИЕ ТЕРМИЧЕСКОЙ ОБРАБОТКИ ЖИДКОГО СПЛАВА НА ЕГО СВОЙСТВА В РАСПЛАВЛЕННОМ СОСТОЯНИИ И ПОСЛЕ АМОРФИЗАЦИИ
}

\author{
(C) 2020 г. П. С. Попель ${ }^{a}$ *, В. Е. Сидоров ${ }^{a}$, М. Кальво-Дальборг ${ }^{b}$, \\ У. Дальборг ${ }^{b}$, В. В. Молоканов ${ }^{c}$ \\ ${ }^{a}$ Уральский государственный педагогический университет, Екатеринбург, Россия \\ ${ }^{b}$ Университет Руана, Нормандия, Руан, Франция \\ ${ }^{c}$ Институт металлургии и материаловедения им. А.А. Байкова РАН, Москва, Россия \\ *e-mail:pspopel@mail.ru
}

Поступила в редакцию 31.01.2020 г.

После доработки 11.02.2020 г.

Принята к публикации 17.02.2020 г.

На основании изложенных ранее представлений о возможности регулирования строения жидких сплавов путем вариации температуры нагрева высказана идея о перспективности использования оптимизированной термической обработки исходных расплавов для стабилизации свойств перспективных жидкометаллических теплоносителей ядерных реакторов. Эта идея подтверждена результатами изучения свойств жидких бинарных эвтектик свинец-висмут, свинец-олово и галлий-индий. Экспериментально получены свидетельства их метастабильной микрогетерогенности, которая может сохраняться в широких интервалах температуры в течение длительного времени после плавления теплоносителя. Показано, что изменение способа приготовления расплава не оказывает существенного влияния на степень его гетерогенности и температуру перехода в гомогенное состояние. Определены основные пути устранения влияния указанной микрогетерогенности на безопасность работы реактора. Обсуждается возможность повышения качества аморфных лент, получаемых методом быстрой закалки и объемно-аморфных сплавов в результате оптимизации температурных режимов их выплавки. Влияние термообработки исходного расплава на строение и свойства аморфных образцов, получаемых традиционным методом спиннингования, показано на примере ряда систем. Установлено, что нагрев жидкого металла над границей существования метастабильной микрогетерогенности способствует формированию более неупорядоченной аморфной структуры по сравнению со стандартной технологией выплавки и позволяет существенно расширить концентрационный диапазон его аморфизации. Показана эффективность и нагрева микрогетерогенного расплава до температур его промежуточных структурных перестроек между двумя микрогетерогенными состояниями, проявляющаяся не только в лабораторных экспериментах, но и в полномасштабном производстве аморфных лент. Для понимания причин формирования объемно аморфных сплавов ключевое значение имеет связь температуры нагрева исходного расплава с его склонностью к глубокому переохлаждению. Обнаружено, что существует специфический интервал температур, побывав в котором, расплав становится склонен к глубокому переохлаждению, причем именно в этом интервале существенно уменьшаются скорость снижения вязкости с ростом температуры и энергия активации вязкого течения. Приводятся представления авторов о причинах такой корреляции.

Ключевые слова: расплавы, оптимизированная термообработка, жидкометаллические теплоносители, скорость закалки, аморфные ленты и объемные аморфные сплавы, структура, свойства

DOI: $10.31857 / \mathrm{S} 023501062003007 \mathrm{X}$ 


\section{ВВЕДЕНИЕ}

Плодотворность термической обработки расплавов для улучшения структуры и свойств полученных из них сталей, чугунов и никелевых сплавов была впервые показана Б.А. Баумом и др. [1]. Результаты, полученные позднее, опубликованы в коллективной монографии [2]. В поисках причин такого влияния П.С. Попель с сотрудниками, на основании результатов изучения температурных зависимостей свойств бинарных металлических расплавов, высказали гипотезу о существовании метастабильных микрогетерогенных состояний, возникающих после плавления гетерогенных исходных материалов и необратимо разрушающихся после нагрева до определенных для каждого состава температур [3]. Эволюцией таких состояний они объяснили вышеуказанное влияние термообработки жидкого металла. Позднее эта гипотеза была однозначно подтверждена У. Дальборгом и М. Кальво-Дальборг в результате их экспериментов по малоугловому рассеянию нейтронов [4]. И.Г. Бродова, П.С. Попель и Г.И. Эскин в книге [5] обобщили свои данные о применении термообработки жидкого металла при производстве алюминиевых сплавов. В работах $[1,2,5]$ речь шла об ее влиянии на кристаллические структуры, возникающие при охлаждении жидкого металла. Однако кристаллизация сопровождается многочисленными сопутствующими процессами, которые в состоянии существенно повлиять на строение формирующихся слитков.

Поэтому в данном обзоре авторы сосредоточили внимание на возможности использования термообработки расплава для регулирования свойств жидкометаллических теплоносителей атомных реакторов и аморфных образцов, которые формируются при его охлаждении с повышенными и умеренными скоростями, полагая, что в этих случаях влияние такой обработки будет более определенным.

\section{НЕОБРАТИМЫЕ ИЗМЕНЕНИЯ СТРОЕНИЯ ПЕРСПЕКТИВНЫХ ЖИДКОМЕТАЛЛИЧЕСКИХ ТЕПЛОНОСИТЕЛЕЙ ЯДЕРНЫХ РЕАКТОРОВ ПРИ ВАРИАЦИИ ИХ ТЕМПЕРАТУРЫ}

Одной из важнейших проблем, возникающих перед проектировщиками новых ядерных реакторов, являются выбор жидкометаллического теплоносителя и разработка технологии обращения с ним. Кроме очевидного требования его совместимости с конструкционными материалами [6], необходимо учитывать, что в критических и нештатных ситуациях температура в активной зоне может изменяться в широких пределах и, в частности, от свойств теплоносителя зависит течение и последствия возможной при этом аварии. Ранее при проектировании ядерных реакторов не учитывалась вероятность необратимых структурных переходов в теплоносителе под действием высоких температур. Причиной этого было использование не сплавов, а чистых металлов, в частности, натрия. Сегодня перспективными их заменителями считаются расплавы свинец-висмут, свинец-олово и галлий-индий эвтектических составов, для которых возможность необратимых перестроек структуры в процессе эксплуатации реакторов уже нельзя игнорировать. Поэтому в [7, 8] мы исследовали условия, при которых происходят необратимые переходы указанных выше жидких эвтектических сплавов из метастабильного микрогетерогенного состояния в состояние истинного раствора.

На рис. 1 приведены значения амплитудного коэффициента поглощения $\alpha$ энергии ультразвуковой волны частотой $f=33.83$ МГц в зависимости от температуры в ходе нагрева образца $\mathrm{Pb}-\mathrm{Bi}$ эвтектической концентрации в течение приблизительно 12 ч после того, как его компоненты были расплавлены, и при последующем охлаждении в том же темпе. Обращает внимание существенное (приблизительно в 5 раз) необратимое уменьшение $\alpha / f^{2}$ при охлаждении расплава после его нагрева до 1370 К. Это свидетельствует о наличии в нагреваемом расплаве неоднородностей, соизмеримых с 


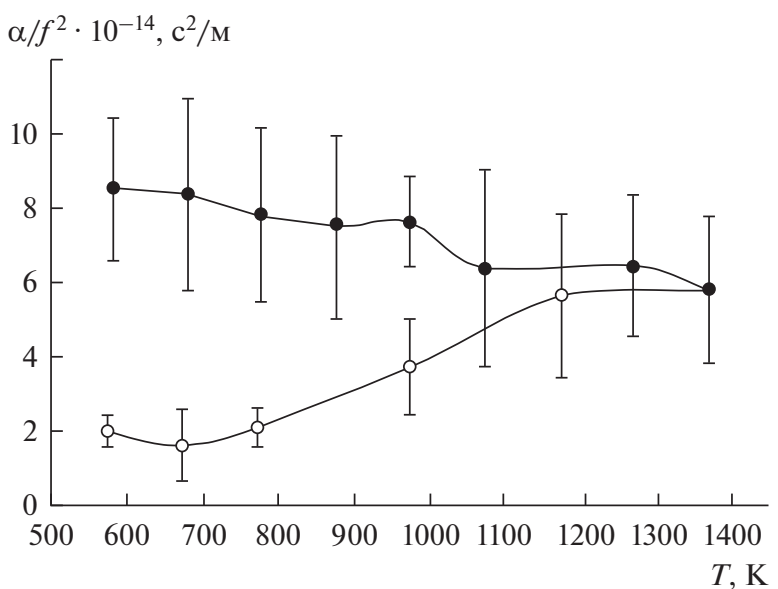

Рис. 1. Температурная зависимость амплитудного коэффициента поглощения ультразвука $\alpha$ в расплаве свинцово-висмутовой эвтектики: - - нагрев, о - охлаждение; вертикальный отрезок у каждой точки в выбранном масштабе соответствует стандартному отклонению результатов измерения коэффициента $\alpha ; f-$ частота ультразвука.

длиной звуковой волны, которые после достижения указанной температуры необратимо разрушаются.

Имея в виду, что при наличии такой крупномасштабной неоднородности должно отмечаться существенное обогащение нижней части образца тяжелым компонентом (в данном случае - свинцом), провели серию опытов, в которых для исследуемых расплавов измеряли скорость ультразвука на различных расстояниях $h$ от дна тигля. Их результаты приведены на рис. 2. Отчетливо проявляется зависимость скорости ультразвука от $h$, постепенно исчезающая при нагреве до $850 \mathrm{~K}$. Как было показано ранее, подобная неоднородность макроскопического свойства по высоте образца размером порядка нескольких сантиметров может наблюдаться только в том случае, если более плотный компонент (свинец) существует в расплаве в виде частиц, содержащих порядка сотен или тысяч его атомов. Таким образом, проведенные опыты явно подтверждают факт микрогетерогенности эвтектического сплава $\mathrm{Pb}-\mathrm{Bi}$ после его плавления, которая разрушается вблизи $850 \mathrm{~K}$.

Подобные результаты были получены и для двух других перспективных жидкометаллических теплоносителей - эвтектических сплавов олово-свинец и индий-галлий. С выводом о наличии дисперсных частиц, обогащенных одним из компонентов, в сплавах $\mathrm{Pb}-\mathrm{Bi}$ и $\mathrm{Sn}-\mathrm{Pb}$ после плавления и их разрушении после нагрева до определенных температур согласуются и результаты вискозиметрического исследования, приведенные в [8].

Для оценки объемной доли дисперсных частиц $\varphi$, обогащенных одним из компонентов, в метастабильной эмульсии расплавов мы использовали гидродинамический подход, впервые примененный в [9]. В этом случае $\varphi$ можно приближенно оценить на основе наших вискозиметрических данных по формуле, уточняющей известную формулу Эйнштейна:

$$
\frac{\eta^{*}}{\eta}=1+2.5 \varphi+6.2 \varphi^{2}
$$




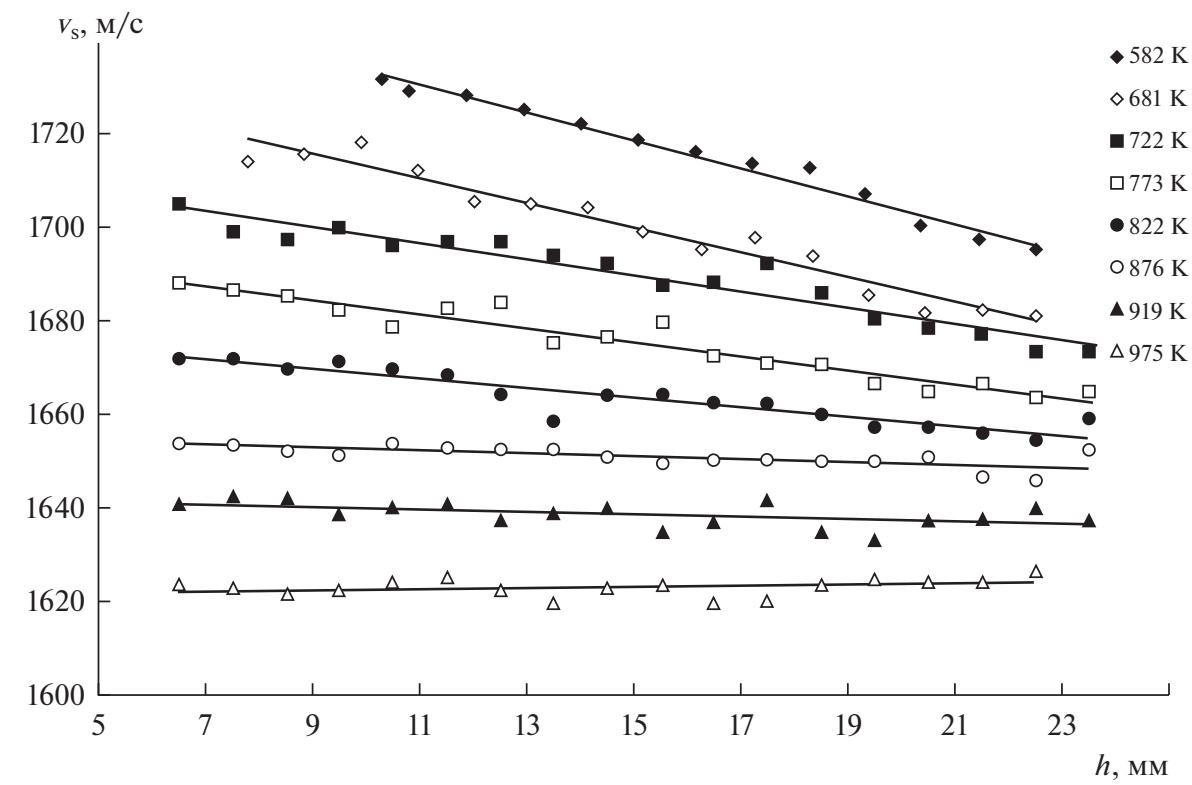

Рис. 2. Зависимости скорости ультразвука в расплаве $\mathrm{Pb}-55.2$ ат. \% Ві от расстояния до дна измерительной ячейки при различных температурах. Сплошные линии - результат линейной аппроксимации экспериментальных данных.

здесь $\eta^{*}$ - динамическая вязкость метастабильной эмульсии, $\eta$ - то же для дисперсионной среды. Пренебрегая незначительным изменением плотности $d$ при образовании микроэмульсии, подобное соотношение можно записать и для измеряемой в наших опытах кинематической вязкости $(v=\eta / d$, где $d-$ плотность). При этом за вязкость дисперсионной среды мы приняли вязкость расплава при его охлаждении от температур, превышающих температуру гомогенизации.

На рис. 3, 4 приведены результаты оценки объемной доли дисперсных частиц в метастабильной микроэмульсии, образующейся при плавлении гетерогенных слитков $\mathrm{Bi}-\mathrm{Pb}$ и $\mathrm{Pb}-\mathrm{Sn}$ при различных температурах. Из их анализа видно, что вблизи температуры ликвидус значения $\varphi$ лежат в пределах $0.1-2.5$ об. \%, что оправдывает применение формулы (1), полученной для разбавленных эмульсий. При приближении к температуре гомогенизации объемная доля дисперсных частиц в микрогетерогенном расплаве постепенно убывает до нуля.

Для каждой изученной системы наряду с расплавами эвтектических концентраций, были исследованы несколько до- и заэвтектических композиций. Результаты также свидетельствуют о необратимом разрушении микрогетерогенности после нагрева до температур гомогенизации $T_{\mathrm{h}}$, характерных для каждого состава. По значениям $T_{\mathrm{h}}$ на фазовых диаграммах систем $\mathrm{Pb}-\mathrm{Sn}$ и $\mathrm{Ga}-\mathrm{In}$ построены границы областей существования метастабильных микрогетерогенных состояний расплавов (рис. 5, 6). Выше указанных кривых их акустические свойства соответствуют термодинамически устойчивому состоянию истинного раствора. При охлаждении после нагрева над этими кривыми гомогенное состояние теплоносителя сохраняется вплоть до его кристаллизации.

Известно, что при температурах, близких к ликвидусу, время жизни метастабильного микрогетерогенного состояния расплавов измеряется сутками. Это обстоятельство нужно принимать во внимание при определении технологических режимов экс- 


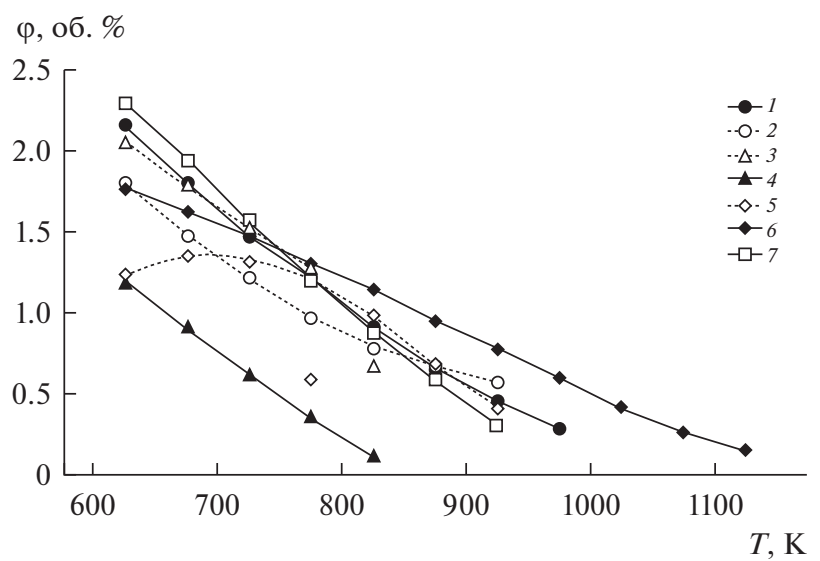

Рис. 3. Результаты оценки объемной доли дисперсных частиц $\varphi$ в расплавах системы Ві-Рb при различных температурах: 1 - 90 ат. \% Pb, 2-80 ат. \% Pb, 3-60 ат. \% Pb, 4-44.5 ат. \% Pb, 5-30 ат. \% Pb, 6-20 ат. \% Pb, $7-10$ ат. $\% \mathrm{~Pb}$.

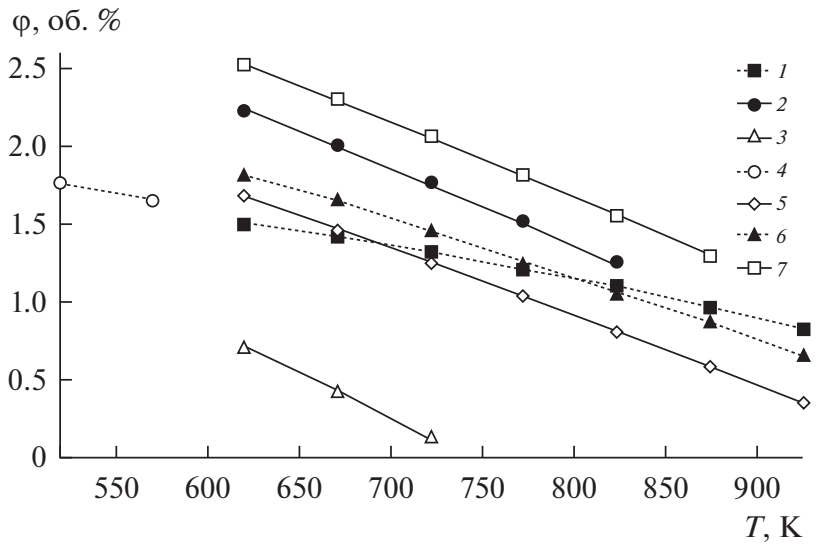

Рис. 4. Результаты оценки объемной доли дисперсных частиц $\varphi$ в расплавах системы $\mathrm{Pb}-\mathrm{Sn}$ при различных температурах: $1-94.02$ ат. \% Sn, $2-87.47$ ат. \% Sn, $3-80.29$ ат. \% Sn, $4-63.58$ ат. \% Sn, $5-42.79$ ат. \% Sn, $6-30.38$ ат. \% Sn, $7-16.24$ ат. \% Sn.

плуатации теплоносителя в течение первых дней его использования в теплообменном контуре ядерного реактора. Определенные в наших опытах температуры гомогенизации вполне могут реализовываться в течение этого времени, что будет сопровождаться необратимым изменением свойств расплава и может привести к возникновению нештатных ситуаций. В числе возможных мероприятий мы рекомендуем либо длительную изотермическую выдержку расплавленного теплоносителя перед началом его циркуляции по контуру, либо его кратковременный нагрев до температур, превышающих указанные выше температуры гомогенизации, либо микролегирование теплоносителя присадками элементов, которые снижают межфазное натяжение на границах дисперсных частиц метастабильной микроэмульсии, определяющее ее устойчивость. 


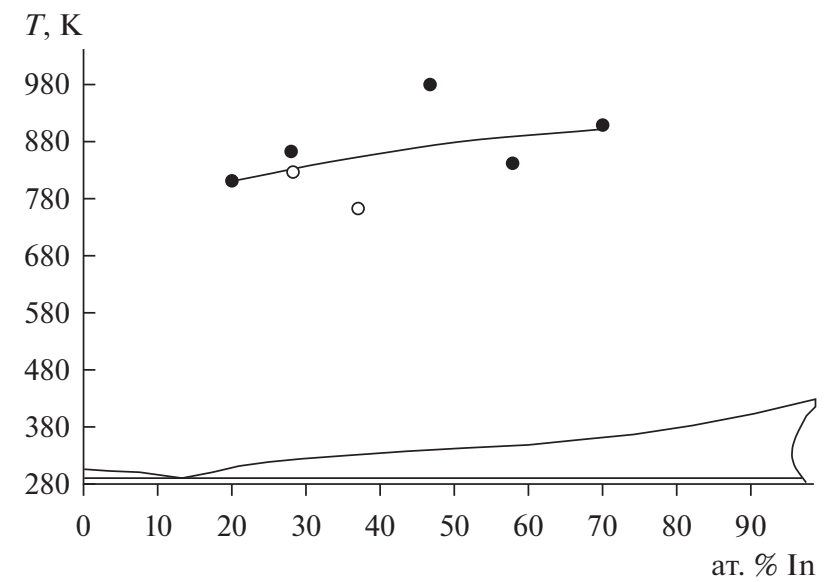

Рис. 5. Граница области существования метастабильной микрогетерогенности на диаграмме состояния системы $\mathrm{Pb}-\mathrm{Sn}$, построенная по результатам акустических опытов с расплавами, приготовленными при нагреве: - закристаллизованного гетерогенного слитка, полученного из негомогенизированного расплава; О - закристаллизованного гетерогенного слитка, полученного из расплава, перегретого выше температуры гомогенизации.

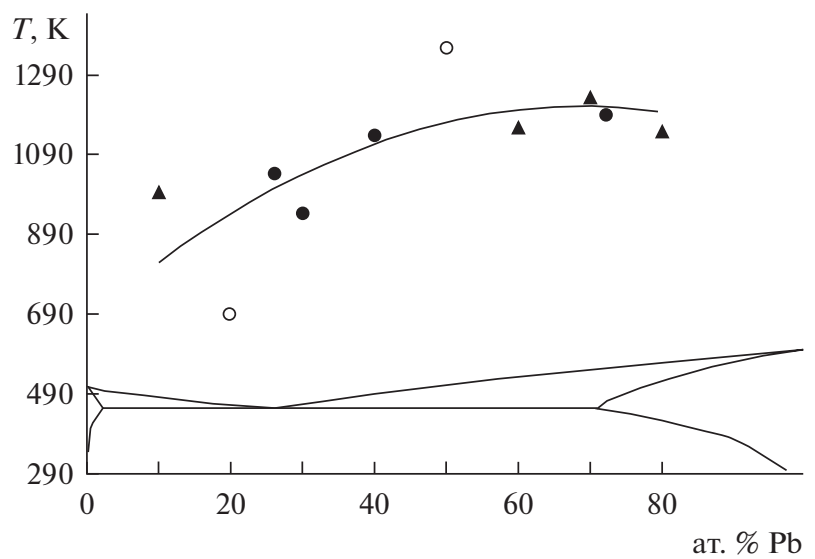

Рис. 6. Граница области существования метастабильной микрогетерогенности на диаграмме состояния системы Ga-In, построенная по результатам акустических опытов с расплавами, приготовленными при нагреве: $\boldsymbol{\Delta}$ - смеси исходных компонентов; - закристаллизованного гетерогенного слитка, полученного из негомогенизированного расплава; о - закристаллизованного гетерогенного слитка, полученного из расплава, перегретого выше температуры гомогенизации.

\section{ТЕРМООБРАБОТКА РАСПЛАВА ПЕРЕД ЕГО СПИННИНГОВАНИЕМ С ЦЕЛЬЮ ПОЛУЧЕНИЯ АМОРФНЫХ ЛЕНТ}

Естественно предположить, что чем выше скорость охлаждения при затвердевании расплава, тем отчетливее его состояние влияет на структуру затвердевшего образца. Следовательно, с одной стороны, быстро закаленные аморфные и нанокристаллические сплавы являются удобными объектами для изучения корреляции между строением жидкости и твердого тела. С другой стороны, оптимизированная термическая обработка жидких металлов с целью повышения их качества после затвердевания 


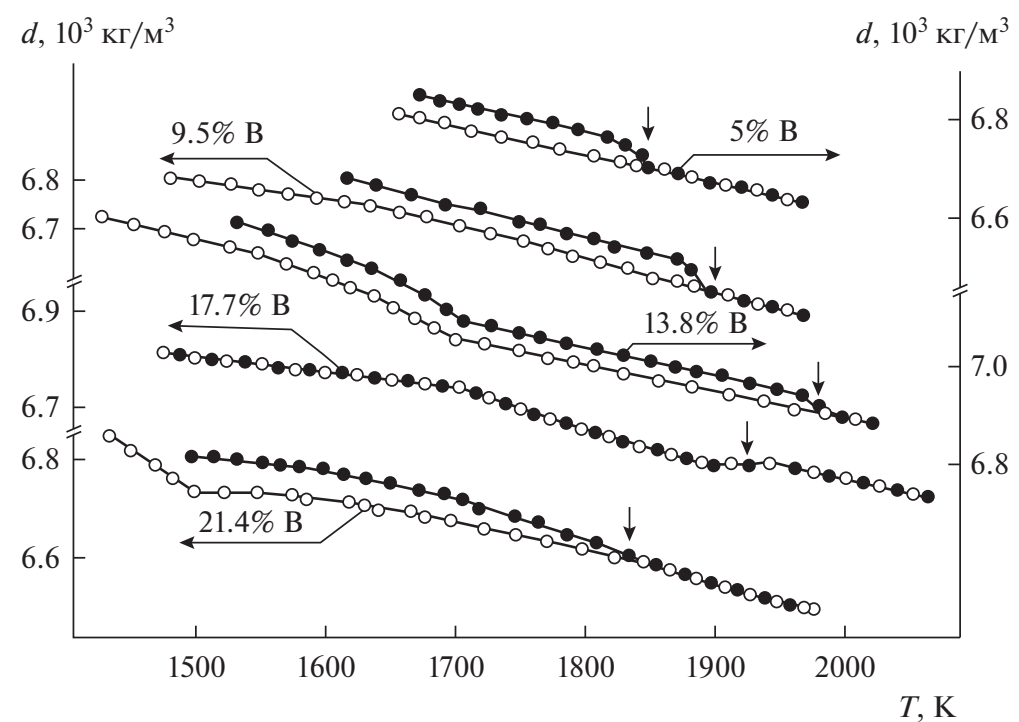

Рис. 7. Температурные зависимости плотности расплавов $\mathrm{Fe}-\mathrm{B}(\bullet-$ нагрев, $\mathrm{O}-$ охлаждение; стрелками показаны высокотемпературные аномалии кривой $d(T))$.

должна быть наиболее эффективна как раз для этих сплавов. Следующие данные подтверждают эту идею.

Начиная с первой работы Дугая и др. [10], было предпринято несколько попыток исследовать влияние температуры исходного расплава на структуру и свойства аморфных лент [11-15]. В большинстве из них, где расплав нагревали над ликвидусом на 100-150 K, это влияние оказалось несущественным. Однако при повышении температуры расплава $\mathrm{Fe}_{83} \mathrm{~B}_{17}$ перед спиннингованием с 1525 до $1625 \mathrm{~K}$ были отмечены некоторые изменения в аморфной структуре и последовательности кристаллизации ее фаз [14]. Новак и др. [15] обнаружили влияние температуры выплавки сплава $\mathrm{Fe}_{83.4} \mathrm{~B}_{16.6}$ на микроструктуру, коэрцитивную силу и намагниченность насыщения металлического стекла. К сожалению, указанные температуры нагрева были выбраны довольно произвольно, не принимая во внимание данных о структуре и свойствах исходных расплавов. Кроме того, авторы одновременно изменяли не только температуру расплава, но и скорость охлаждения. Чтобы установить, как изменения структуры и свойств расплава при нагреве влияют на структуру и свойства аморфных лент, необходимо закаливать расплав при одинаковой скорости охлаждения.

В [16] мы изучали температурные зависимости плотности $d(T)$ жидких сплавов $\mathrm{Fe}-\mathrm{B}$. Результаты, показанные на рис. 7, свидетельствуют о необратимой гомогенизации расплавов при 1870-1930 К в зависимости от содержания бора. Нанеся температуры гомогенизации $T_{\text {hom }}$ для различных составов на фазовую диаграмму системы $\mathrm{Fe}-\mathrm{B}$, получаем куполообразную кривую, внутри которой существует метастабильная микрогетерогенность (рис. 8). Стало ясно, что нагрев расплавов, достигнутый в [10-15], был намного ниже границы этой области. Поэтому эффекты, наблюдаемые в [14, 15], скорее всего, могут быть связаны с некоторыми изменениями в масштабе микрогетерогенности. Более существенный нагрев был достигнут в [17], где исследовалось влияние термической обработки исходного расплава на структуру, плотность и особенности кристаллизации аморфных сплавов $\mathrm{Fe}_{100-x} \mathrm{~B}_{x}(15<x<25$ ат. \%). Почти одинако- 


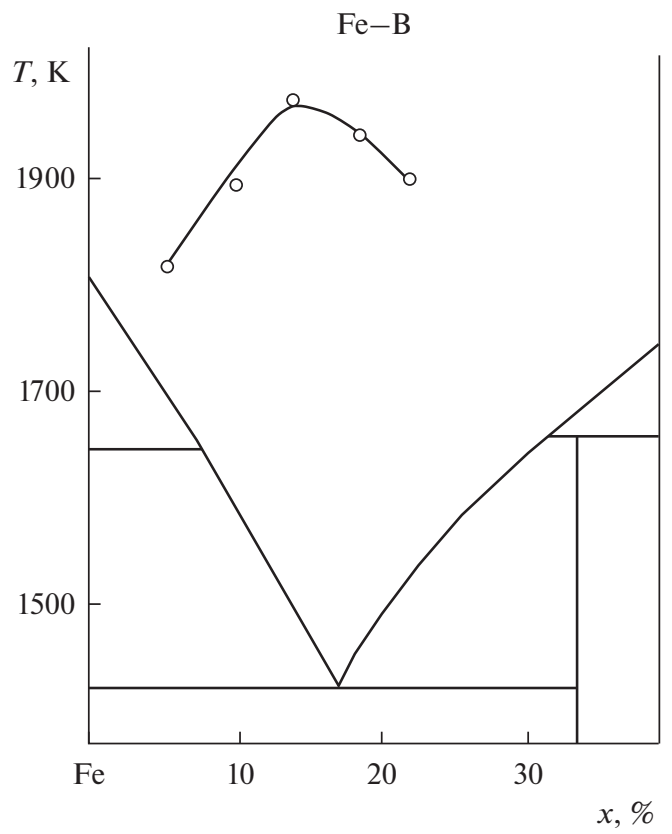

Рис. 8. Куполообразная кривая на фазовой диаграмме системы $\mathrm{Fe}-\mathrm{B}$, внутри которой существует метастабильная микрогетерогенность.

вая скорость охлаждения достигалась за счет изготовления лент одинаковой толщины (20 мКм).

Например, для $\mathrm{Fe}_{80} \mathrm{~B}_{20}$ закалка производилась от 1500, 1580, 1680 и $1780 \mathrm{~K}$ без предварительного нагрева до максимальной температуры опыта и при 1730, 1680, 1630 и $1580 \mathrm{~K}$ после предварительного перегрева расплава до $1880 \mathrm{~K}$ и выдержки при этой температуре в течение 10 мин.

Функции радиального распределения атомов $G(r)$ аморфных образцов различаются по форме второго максимума (рис. 9). Позиции максимумов почти идентичны. По мере роста температуры закалки с 1500 до $1780 \mathrm{~K}$ расщепление второго максимума уменьшается. Выдержка расплава в течение 10 мин при 1880 К перед закалкой приводит к росту расщепления. Оно может быть связано с необратимыми изменениями распределения атомов.

При повышении температуры закалки с 1500 до 1780 К молярный объем аморфных лент $\mathrm{Fe}_{80} \mathrm{~B}_{20}$ постепенно возрастает с 6.35 до $6.44 \mathrm{~cm}^{3}$ моль ${ }^{-1}$. После выдержки расплава при $1880 \mathrm{~K}$ температурная зависимость молярного объема достигает максимума вблизи $1680 \mathrm{~K}$ (рис. 10a). Зависимости температуры начала кристаллизации и теплоты кристаллизации от начальной температуры расплава подобны кривой объема (рис. 10б, 10в). При закалке расплава от 1500 и 1580 К без предварительного нагрева до максимальной температуры и от 1730, 1680, 1630 и 1580 К после предварительного нагрева до $1880 \mathrm{~K}$ кристаллизация является эвтектической (кристаллы $\alpha-\mathrm{Fe}$ и $\left.\mathrm{Fe}_{3} \mathrm{~B}\right)$. При закалке от 1680 и 1780 К без предварительного нагрева до 1880 К кристаллизация проходит в два этапа. На первом выделяются кристаллы $\alpha-\mathrm{Fe}$.

Эти результаты подтверждают начало необратимого структурного преобразования расплава после его изотермической выдержки при 1880 К. Поскольку влияние этой 


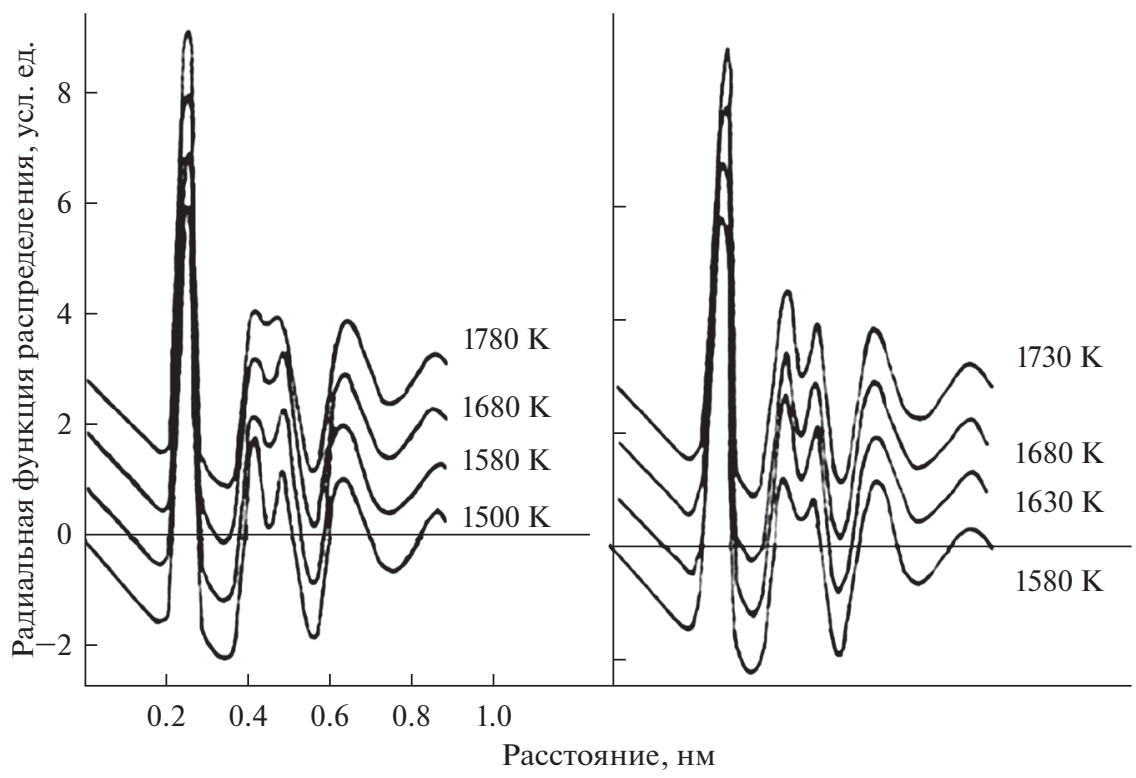

Рис. 9. Функции радиального распределения атомов $G(r)$ аморфных лент $\mathrm{Fe}_{80} \mathrm{~B}_{20}$, закаленных от различных температур [17].

выдержки проявляется в максимальной степени при последующем охлаждении до $1680 \mathrm{~K}$, можно предположить, что при $1880 \mathrm{~K}$ микрогетерогенность расплава не была разрушена полностью, и процесс гомогенизации продолжился на начальных этапах его охлаждения. Затем микрогетерогенность расплава снова начинает нарастать с уменьшением температуры закалки, и свойства расплава приближаются к их начальным значениям.

B [16], расплавы Fe-B были нагреты на 50-100 К над границей существования метастабильной микрогетерогенности (рис. 8) и закалены от обычной температуры литья. Судя по результатам рентгеновской дифракции и мессбауэровской спектроскопии, такая термическая обработка способствует формированию более неупорядоченной аморфной структуры, чем стандартная технология выплавки.

Влияние термической обработки расплава на механические свойства и стеклообразующую способность сплавов $\mathrm{Al}-\mathrm{La}-\mathrm{Ni}$ и $\mathrm{Al}-\mathrm{Ce}-\mathrm{Ni}$ исследовалось в [18]. Важное промышленное применение аморфных сплавов на основе алюминия связано с их прекрасными механическими свойствами, которые существенно превосходят прочность и пластичность кристаллических алюминиевых сплавов [19]. В частности, аморфные сплавы Al-La-Ni, содержащие более 80 ат. \% Al, могут быть полностью согнуты на $180^{\circ}$ без образования больших трещин и без заметного растрескивания в сильно деформированной области [20]. Пластичность этих сплавов в значительной степени зависит от их состава, и существует четкая тенденция к повышению пластичности с ростом содержания алюминия. Однако все попытки получения аморфных сплавов с концентрацией $\mathrm{Al}$ более 90 ат. \% были безуспешными до того момента, когда мы определили температуру гомогенизации расплава.

В [18] были измерены температурные зависимости вязкости и поверхностного натяжения сплавов $\mathrm{Al}_{91} \mathrm{La}_{5} \mathrm{Ni}_{4}$ и $\mathrm{Al}_{91} \mathrm{Ce}_{5} \mathrm{Ni}_{4}$ в жидком состоянии. Результаты исследования первого из них приведены на рис. 11. Эти кривые свидетельствуют о необратимом 


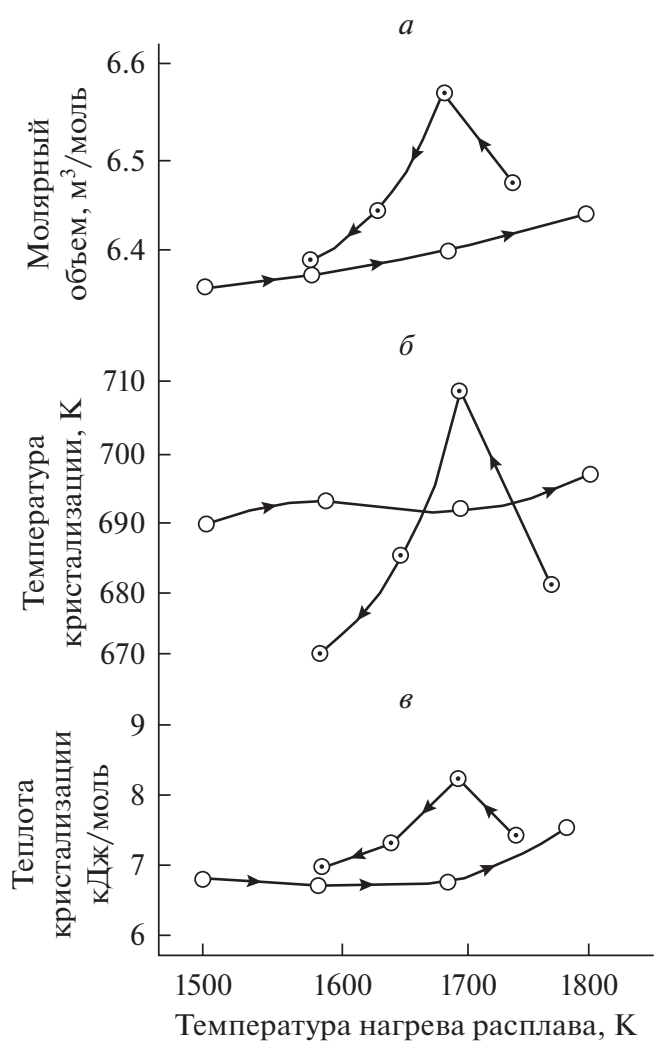

Рис. 10. Молярный объем $V(a)$, температура кристаллизации $T_{\mathrm{c}}\left(\right.$ б) и удельная теплота кристаллизации $\Delta H_{\mathrm{c}}$

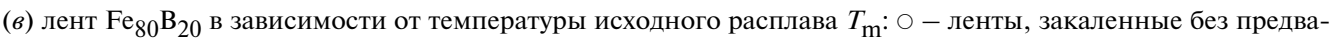
рительного нагрева расплава до $1880 \mathrm{~K}$; $\odot$ - ленты, закаленные после предварительного нагрева расплава до $1880 \mathrm{~K}[17]$.

перераспределении атомов расплава при $1150 \mathrm{~K}$ (согласно точке ветвления вискозиметрических данных) или при 1220 К (согласно результатам измерения поверхностного натяжения).

Необратимые изменения свойств в интервале 1150-1220 К могут быть связаны с переходом жидкого сплава из метастабильного микрогетерогенного состояния в состояние истинного раствора. Мы полагаем, что после плавления первоначально гетерогенного слитка унаследованные от него наноразмерные частицы с составами, близкими $\mathrm{K} \mathrm{Al}_{4} \mathrm{La}$ или $\mathrm{Al}_{4} \mathrm{Ce}$, длительное время сохраняются в расплаве, незначительно перегретом над ликвидусом, и необратимо разрушаются только после его нагрева до 1150-1220 К. Такая микрогетерогенная структура может препятствовать формированию аморфной структуры при спиннинговании.

Быстро затвердевшие ленты были получены с использованием различных видов термической обработки расплава. Проведено две серии экспериментов. В первой из них жидкий сплав выдерживался в течение 5 мин при 1070, 1170, 1270, 1370, и $1470 \mathrm{~K}$. Во второй он выдерживался в течение 10 мин при $1470 \mathrm{~K}$, а затем в течение 5 мин при 1270 и 1370 К. Ленты, затвердевшие от 1070 и 1170 K, оказались хрупкими и кристаллическими, тогда как ленты, закаленные от более высоких температур, были пластичны- 

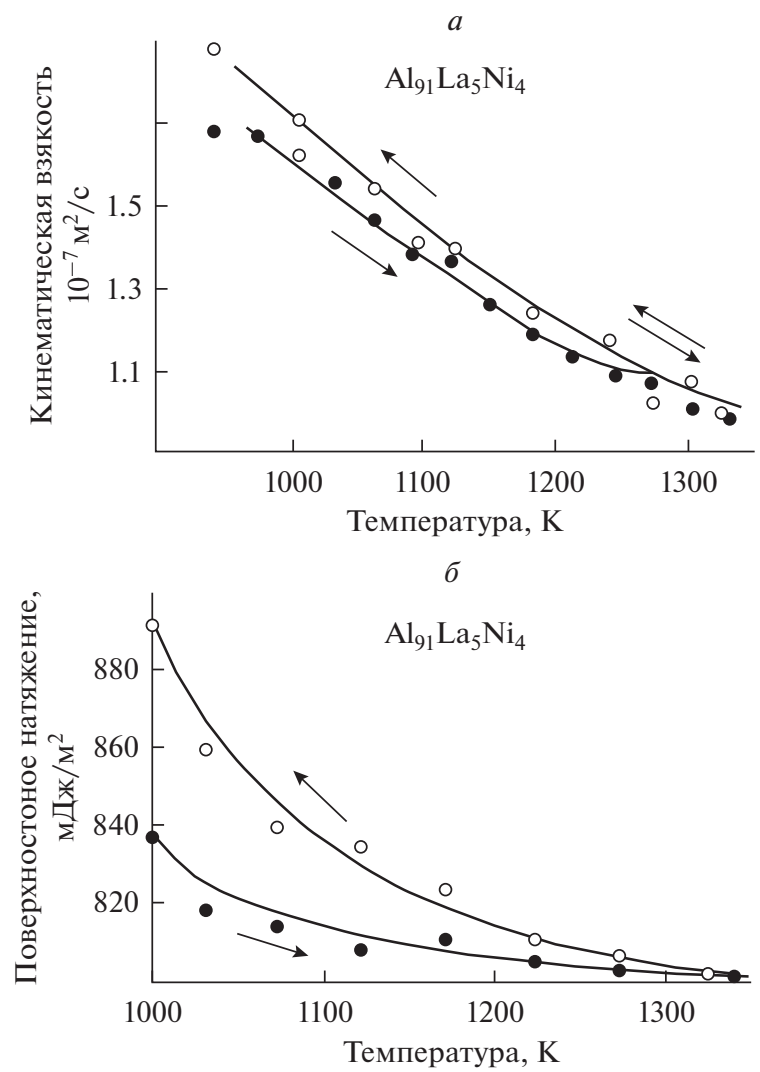

Рис. 11. Температурные зависимости вязкости (a) и поверхностного натяжения (б) расплава $\mathrm{Al}_{91} \mathrm{La}_{5} \mathrm{Ni}_{4}:$ направления изменения температуры указаны стрелками [18].

ми и аморфными. Таким образом, необратимая гомогенизация расплавов существенно повлияла на формирование аморфных образцов $\mathrm{Al}_{91} \mathrm{La}(\mathrm{Ce})_{5} \mathrm{Ni}_{4}$. Даже нагрев в жидком состоянии выше всего 1220 К позволил получить аморфные ленты, проявляющие высокую пластичность на изгиб.

В нескольких количественных исследованиях сообщается о влиянии термической обработки расплава на механические свойства аморфных сплавов других систем [21-27]. В [21] дан обзор различных путей улучшения аморфной структуры, повышения качества и механических свойств металлических лент. В $[21,22,25,26]$ нами было проведено исследование аморфизирующихся сплавов $\mathrm{Fe}_{85} \mathrm{~B}_{15}, \mathrm{Fe}_{64} \mathrm{Co}_{21} \mathrm{~B}_{15}$ и $\mathrm{Ni}_{81} \mathrm{P}_{19}$. В каждом случае испытывались по три ленты, закаленные из трех различных состояний расплавов, которые были выбраны на основании кривых вязкость-температура, полученных в режимах нагрева и последующего охлаждения (рис. 12). Судя по этим кривым, их необратимая гомогенизация происходит при температурах, значительно превышающих как обычные температуры серийной выплавки, так и возможности соответствующих промышленных агрегатов. Поэтому мы обратили внимание на отчетливые признаки промежуточных структурных перестроек жидкого металла между двумя микрогетерогенными состояниями. Эти признаки отчетливо наблюдаются в виде особенностей температурных зависимостей вязкости, полученных в ходе нагрева образца после 

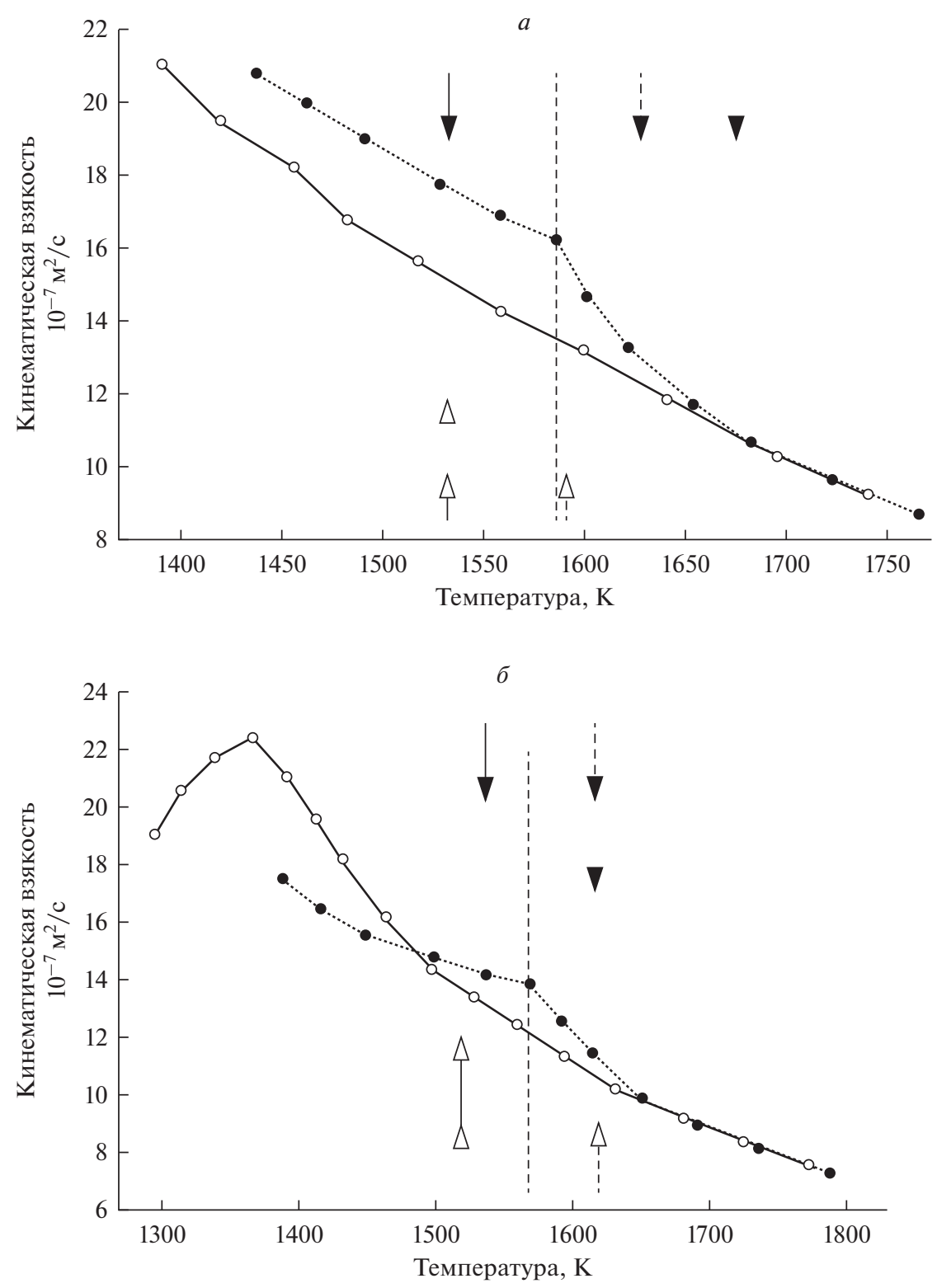

Рис. 12. Температурные зависимости кинематической вязкости $v$ жидких $a$ ) $\mathrm{Fe}_{85} \mathrm{~B}_{15}$ и б) $\mathrm{Fe}_{64} \mathrm{Co}_{21} \mathrm{~B}_{15}$ нагрев, $О$ - охлаждение. Сплошные стрелки показывают максимальную температуру нагрева расплава, а пустые стрелки - температуру закалки образцов серии I (сплошная линия), серии II (пунктирная линия) и серии III (стрелка без линии). Вертикальная пунктирная линия показывает температуру растворения $T_{\mathrm{d}}$.

плавления, при 1570 К для сплавов на основе железа и при 1370 К для сплава на никелевой основе. После этого для каждого состава были получены по три серии аморфных лент: серия 1 была закалена от температуры ниже указанной точки промежуточного перехода, серия 2 - от температуры, превышающей ее на 60-100 K, и серия 3 - от 

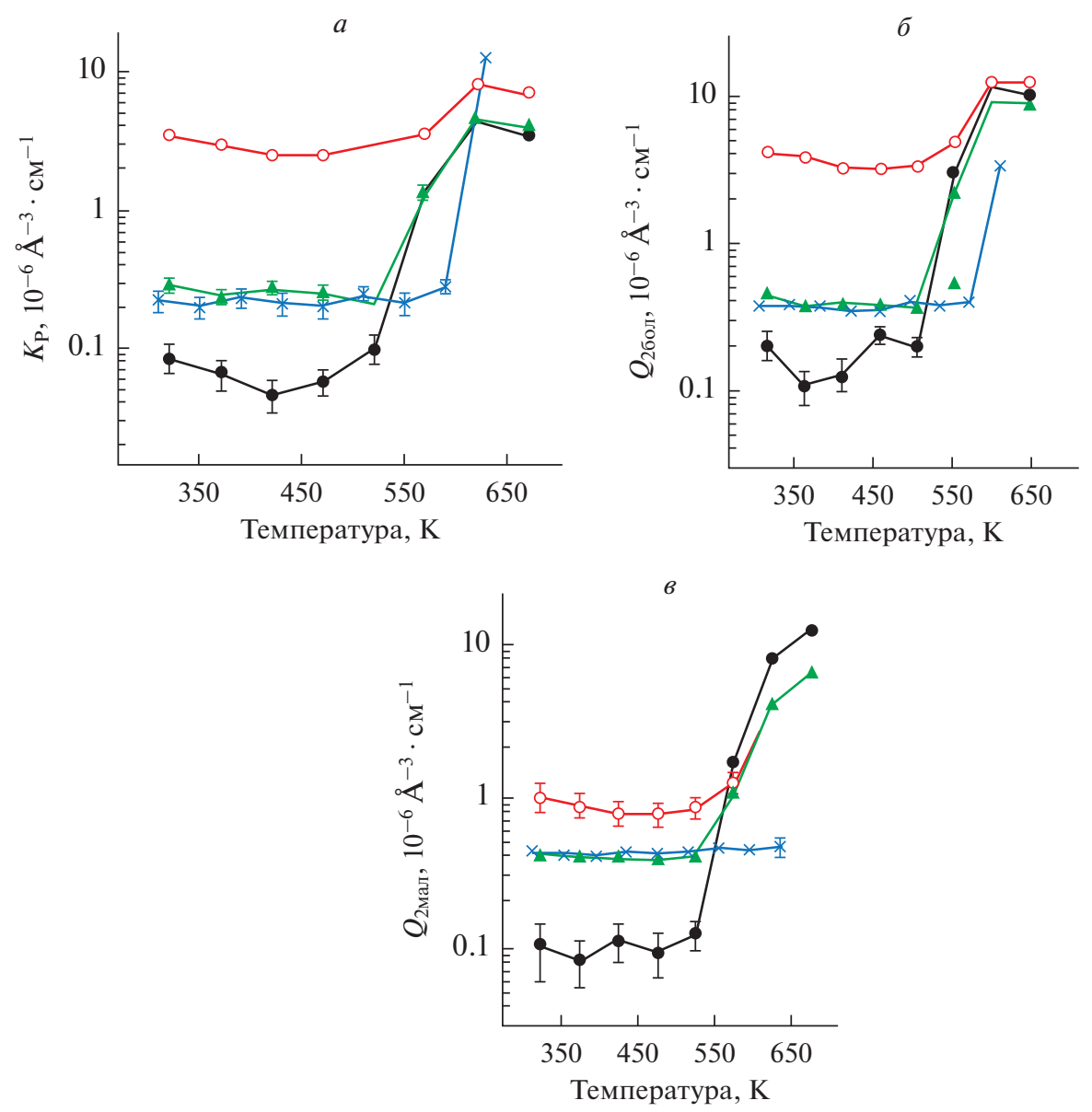

Рис. 13. Постоянная порода $(a)$ и инвариант $Q_{2}$ для семейств (б) больших и (в) малых частиц для образцов 651 (черные квадраты), 652 (красные кружочки), 653 (зеленые треугольники) и лент, полученных по серийной промышленной технологии (синие крестики).

той же температуры, что серия 1, но после нагрева расплава до той же температуры, что в серии 2. Исходя из результатов исследования структуры ближнего порядка, полученных методом дифракции нейтронов [26], микроструктуры - методом малоуглового рассеяния нейтронов [26, 27], и из производственных параметров, предоставленных компанией-производителем, могут быть сопоставлены условия закалки лент $\mathrm{Fe}_{64} \mathrm{Co}_{21} \mathrm{~B}_{15}$ и $\mathrm{Ni}_{81} \mathrm{P}_{19}$ и их строение.

При исследовании лент Ni-P методом дифракции нейтронов установлено, что во всех трех указанных выше сериях еще при комнатной температуре существовали кристаллические частицы, но после нагрева расплавов их микроструктура развивалась различными путями. Для того, чтобы это проиллюстрировать, на рис. 13 показаны изменения с температурой двух характерных параметров: константы Порода $K_{\mathrm{P}}$ и инварианта $Q_{2}$. $K_{\mathrm{P}}$ пропорциональна полной поверхности дисперсных частиц в образце, а $Q_{2}-$ концентрации этих частиц. 
Из данных, полученных методом малоуглового рассеяния нейтронов, который фиксировал микрочастицы в диапазоне размеров 1-100 нм, для шести указанных выше образцов можно сделать следующие выводы относительно существования в них таких частиц и их размеров $[22,26]$.

Для $\mathrm{Ni}_{81} \mathrm{P}_{19}$ :

- Образцы серии 2 содержат значительное количество включений двух семейств, одно из которых имеет средний размер около 100 нм а второе - около 20 нм. Последнее семейство образовано в основном мелкими кристаллами $\mathrm{Ni}_{3} \mathrm{P}$ и в меньшей степени - чистым Ni.

- Образцы серии 3 содержат два семейства включений размерами, подобными семейству 2: крупные в количестве в 3-4 раза меньшем и мелкие, которых меньше в 10 и более раз.

- Образцы серии 1 содержат меньшее количество крупных частиц по сравнению с серией 3 и еще меньшее количество мелких. Однако температура кристаллизации мелких ниже, чем в сериях 2 и 3. Образцы серии 1, так же, как и образцы серии 2, но в гораздо меньшей степени, демонстрируют фазовый переход от пластичного аморфного к хрупкому аморфному состоянию вблизи $420 \mathrm{~K}$.

Для $\mathrm{Fe}_{64} \mathrm{Co}_{21} \mathrm{~B}_{15}$ :

- Образец серии 2 содержит многочисленные крупные включения со средним размером около 80 нм и малые - около 10 нм. Малые, вероятно, являются кристаллитами.

- Образец серии 1 содержит те же типы включений, что и в серии 2, но значительно меньшее количество малых включений.

- Образец серии 3 также содержит большие включения, однако в гораздо меньшем количестве, чем в сериях 2 и 3 , но не содержит мелких.

Исследование полученных лент методом дифференциальной сканирующей калориметрии (ДСК) проведено на калориметре Perkin-Elmer DSC7. Наблюдались следующие общие тенденции:

- Образцы серии 1, которые были закалены при низкой температуре без перегрева, демонстрируют позднее начало кристаллизации $\alpha-\mathrm{Fe}$, но раннее начало кристаллизации борида.

- Образцы серии 2, которые были закалены от максимальной температуры, обнаруживают самое раннее начало кристаллизации $\alpha-F e$, но самое позднее для боридов.

- Образцы серии 3, которые были закалены от низкой температуры после предварительного перегрева, демонстрируют раннее начало кристаллизации как $\alpha-\mathrm{Fe}$, так и боридов.

Для классификации и описания аморфного состояния быстро закаленных лент в рамках механики разрушения в [21-23] мы использовали статистику Вейбулла и фрактографический анализ.

Для сплавов $\mathrm{Ni}-\mathrm{P}$ и $\mathrm{Fe}-\mathrm{Co}-\mathrm{B}$ вейбулловский анализ приводит к следующим заключениям:

- Ленты как $\mathrm{Ni}_{81} \mathrm{P}_{19}$ (образец 653), так и $\mathrm{Fe}_{64} \mathrm{Co}_{21} \mathrm{~B}_{15}(646)$, полученные в серии 3 после перегрева с подстуживанием, являются наиболее гомогенными. В частности, модуль Вуйбулла ленты (653) является вообе довольно высоким для аморфных металлических лент.

- Образцы $\mathrm{Ni}-\mathrm{P}$ гораздо более однородны, чем образцы тройного сплава $\mathrm{Fe}-\mathrm{Ni}-$ Со, для которых значения модуля Вейбулла близки к средним величинам, обычно определяемым для металлических стекол, и даже более низким для образца (647).

- Ni-P (651) и Ni-P (652) имеют довольно близкие дисперсии, по сравнению с наиболее однородным (653), тогда как все три образца Fe-Co-B отличаются друг от друга. 
Результаты тестов на растяжение в рамках статистики Вейбулла показывают, что ленты как $\mathrm{Ni}_{81} \mathrm{P}_{19}$, так и $\mathrm{Fe}_{64} \mathrm{Co}_{21} \mathrm{~B}_{15}$, полученные в сериях 3 , являются наиболее однородными, в особенности первые из них, для которых модуль Вейбулла является довольно высоким по сравнению с большинством металлических стекол. Эти же ленты разрушаются при самых высоких напряжениях разрушения, а образцы серии 2 - при самом низком. Из этих результатов становится очевидным, что имеет место значительное влияние состояния исходного расплава перед закалкой на качество и механические свойства полученных из него аморфных лент, поскольку для двух типов сплавов это влияние является систематическим и коррелирует с условиями производства. Подобные выводы могут быть сделаны и из результатов опытов по нейтронной дифракции и малоугловому рассеянию нейтронов [28, 29].

Для детального фрактографического анализа были выбраны несколько образцов в соответствии с их напряжениями излома и условиями разрушения. Поверхности их излома изучались методом сканирующей электронной микроскопии (СЭМ). Из полученных результатов можно сделать следующие заключения:

Для $\mathrm{Ni}-\mathrm{P}$ :

- Матрица образцов (651) представляет поверхности излома, покрытые венозными линиями нормальной плотности. Детектируемые вмороженные дефекты, ответственные за зарождение трещин, относятся к когерентному типу и расположены около пор.

- Образцы (652) представляют матрицу из плотных вен. Детектируемые дефекты принадлежат к некогерентному типу, очень многочисленны и локализованы близко к порам.

- Матрица образцов (653) состоит из вен пониженной плотности. Детектируемые дефекты также принадлежат к некогерентному типу и расположены вблизи пор, однако их количество и размеры меньше, чем в (652).

Для $\mathrm{Fe}-\mathrm{Co}-\mathrm{B}$ :

- Образцы (645) представляет собой матрицу плотных вен и грубых шевронов. Детектируются дефекты обоих типов: когерентные и некогерентные.

- Матрица образцов (646) представляет поверхность излома, покрытую венозными линиями низкой плотности, безо всяких следов шевронов. Детектируемые вмороженные дефекты, ответственные за зарождение трещин, принадлежат к когерентному типу и расположены вблизи пор.

- Матрица образцов (647) состоит из плотных вен и шевронов. Детектированы дефекты обоих типов: когерентные и некогерентные.

В других работах приводятся результаты исследования механических свойств аморфных металлических лент, подтверждающие влияние на них состояния расплава перед закалкой [28, 29]. Были измерены и их магнитные свойства: индукция насыщения $B_{\mathrm{s}}$, остаточная намагниченность $B_{\mathrm{r}}$ и коэрцитивная сила $H_{\mathrm{c}}$ так же, как и их изменения со временем отжига.

Приведенные выше результаты были получены в лабораторных условиях. Представляло интерес выяснить, в какой степени термическая обработка расплава может быть эффективной в полномасштабном производстве аморфных металлических лент. С этой целью на промышленном оборудовании компании Advanced Metal Technologies Ltd. (Израиль) методом спиннингования расплава были проведены три серии опытных плавок лент из сплава $\mathrm{Co}_{68} \mathrm{~B}_{12} \mathrm{Si}_{12} \mathrm{Fe}_{4.2} \mathrm{Cr}_{3.8}$ [27]. Вместимость печи составляла 30 кг. В ходе первой серии расплав нагревали до $1750 \mathrm{~K}$, а затем закаливали от этой же температуры (режим 1). В ходе последующих экспериментов его нагревали до $1775 \mathrm{~K}$ и разливали от этой же температуры (режим 2) или нагревали до $1815 \mathrm{~K}$, затем охлаждали до 1775 К и закаливали с той же скоростью, что и в предыдущей серии (режим 3). Изотермическая выдержка перед разливкой во всех опытных плавках составляла 10 мин. Поскольку температура закалки и толщина лент (21.3 мкм) были близки во всех трех режимах, разница в скорости охлаждения расплава была несущественной. 
Таким образом, различия в свойствах полученных лент могут быть связаны с различными температурами нагрева расплава перед спиннингованием.

Для лент этого сплава, подготовленных по трем упомянутым выше режимам, сопоставляли параметры петель гистерезиса при 100 кГц - максимальной частоте его использования в качестве магнитомягкого материала с высокой магнитной проницаемостью. Установлено, что повышение температуры нагрева расплава от 1750 до $1815 \mathrm{~K}$ не изменило магнитную индукцию при напряженности поля 8 А/м $(0.53,0.53$ и 0.51 Тл для режимов 1, 2 и 3, соответственно). Однако коэрцитивная сила ленты, подготовленной с использованием режима 3 , была значительно ниже по сравнению с аналогом, подготовленным после более низкого нагрева исходного расплава (18 А/м вместо $22-23$ А/м). Индукция насыщения $B_{\mathrm{m}}$ этой ленты на частоте 100 кГц отличается от ее значения при 50 Гц только на 6\%. Кроме того, в отличие от аналогов, ее свойства оказались не чувствительны к температуре последующего отжига.

Таким образом, термическая обработка расплава в полномасштабном производстве аморфных лент позволила получить магнитомягкий материал с более высокими эксплуатационными свойствами.

\section{СВЯЗЬ СТРУКТУРНОГО СОСТОЯНИЯ ИСХОДНОГО РАСПЛАВА С ЕГО СКЛОННОСТЬЮ К ФОРМИРОВАНИЮ ОБЪЕМНО АМОРФНЫХ СПЛАВОВ}

Начиная с 1988 г., в Японии под руководством А. Иноуе были успешно разработаны многокомпонентные системы сплавов на основе магния, лантана, циркония, железа, титана, никеля и, более узко, - систем $\mathrm{Pd}-\mathrm{Cu}$ и $\mathrm{Pd}-\mathrm{Fe}$, которые аморфизировались при аномально низких скоростях охлаждения (вплоть до $0.1 \mathrm{~K} / \mathrm{c}$ ). Из них удавалось получить аморфные слитки размером до 100 мм, вполне достаточным для производства объемных аморфных изделий. Этот тип металлических объектов получил название объемно аморфных сплавов (ОАС). В своем обзоре [30] А. Иноуе сообщил краткую историю открытия, составы, структуру, способы получения и основные свойства ОАС. Он обратил внимание на необходимость существенного повышения вязкости исходного расплава перед его аморфизацией. Последнее положение было экспериментально подтверждено П.С. Попелем, который в 1999 г. обнаружил, что вязкость одного из ОАС при температурах, близких к температуре стеклования, превышает вязкость обычных металлических расплавов в несколько десятков раз.

Существенный вклад в разработку перспективных составов ОАС внесла группа исследователей под руководством В.В. Молоканова [31, 32]. По-видимому, они в числе первых пытались связать стеклообразующую способность (СОС) этих сплавов со строением их жидких прекурсоров. До этого связь между температурой нагрева исходного расплава и его склонностью к глубокому переохлаждению (СГП), предшествующему формированию ОАС, изучалась в [33-35], а для сплава $\mathrm{Zr}_{52.5} \mathrm{Cu}_{17.9} \mathrm{Ni}_{14.6} \mathrm{Ti}_{5} \mathrm{Al}_{10}$, образующего объемно аморфные слитки - в [36]. Было показано, что нагрев расплава $\mathrm{Zr}_{57} \mathrm{Ti}_{5} \mathrm{Ni}_{8} \mathrm{Al}_{10} \mathrm{Cu}_{20}$ до $1520^{\circ} \mathrm{C}$ приводит к увеличению толщины аморфного слоя в объемном металлическом стекле $\mathrm{Zr}_{57} \mathrm{Ti}_{5} \mathrm{Ni}_{8} \mathrm{Al}_{10} \mathrm{Cu}_{20}$ до 20 мм [37].

В.В. Молоканов с соавторами [27, 38-40] выполнили серию работ с целью выделения основных факторов, влияющих на возможность получения объемных аморфных сплавов, их строение и свойства. В [27, 38] они исследовали влияние термической обработки расплава на склонность к глубокому переохлаждению и стеклообразующую способность композиций $\mathrm{Fe}_{76.6} \mathrm{Ni}_{1.3} \mathrm{Si}_{8.6} \mathrm{~B}_{13.5}, \mathrm{Co}_{69.6} \mathrm{Fe}_{1.3} \mathrm{Mn}_{4.5} \mathrm{Si}_{14.3} \mathrm{~B}_{9.3} \mathrm{Mo}_{1} \quad$ и $\mathrm{Fe}_{87} \mathrm{P}_{8.2} \mathrm{C}_{1.8} \mathrm{Cu}_{1.5} \mathrm{Sn}_{1.5}$ (далее, сплавы 1, 2 и 3, соответственно). Осуществлялся термический цикл нагрев-охлаждение с многократным пересечением интервала плавлениякристаллизации. Температура расплава постепенно повышалась, а время отжига сохранялось близким к 60 с. Переохлаждение относительно температуры плавления мо- 


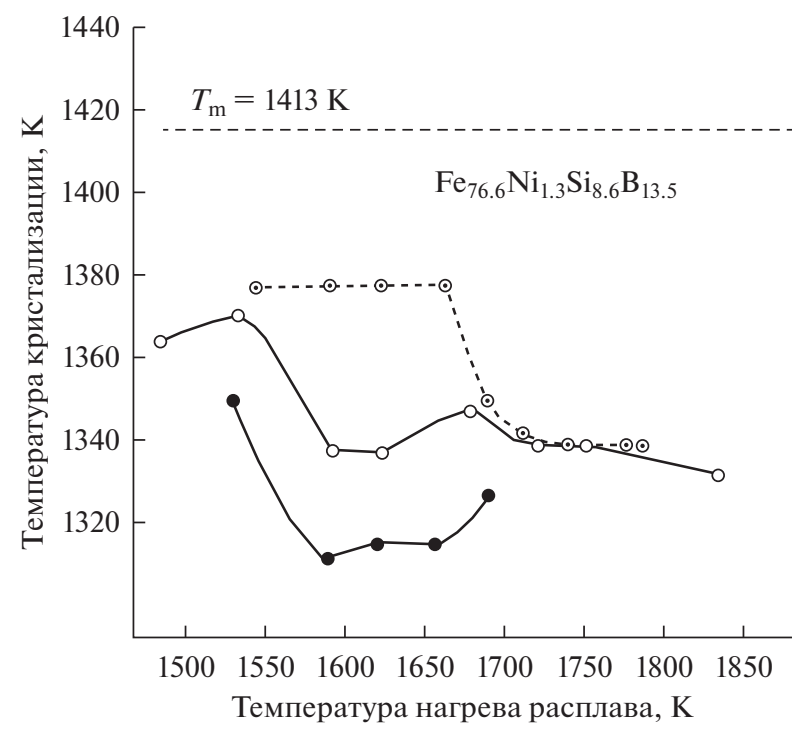

Рис. 14. Зависимость температуры кристаллизации сплава $\mathrm{Fe}_{76.6} \mathrm{Ni}_{1.3} \mathrm{Si}_{8.6} \mathrm{~B}_{13.5}$ от температуры нагрева исходного расплава: $\odot$ - слиток; О - гранулы (3 мм); - гранулы (0.3 мм).

ниторировалось по положению острого экзотермического пика на кривых ДТА и с высокой точностью регистрировалось для данных условий охлаждения по резкому снижению температуры кристаллизации. Было обнаружено, что все исследованные расплавы могут быть переохлаждены ниже температуры плавления $T_{\mathrm{m}}$. Способность к переохлаждению определялась как $T_{\mathrm{m}}-T_{\mathrm{cr}}\left(T_{\mathrm{cr}}-\right.$ температура кристаллизации). Было обнаружено, что существует специфический интервал температуры нагрева расплава, побывав в котором он становится склонен к глубокому переохлаждению. СГП расплавленных образцов массивных слитков при термоциклировании возрастает после их нагрева над ликвидусом на 290, 510 и $180 \mathrm{~K}$ и выше для сплавов 1, 2 и 3 соответственно. Нагрев сплавов 1 и 3 над ликвидусом на 520 и 590 К сопровождается уменьшением СГП. Существенное снижение низкотемпературной границы интервала легкого переохлаждения до 250 К над ликвидусом было получено для сплава 1 после того, как в жидком состоянии он был изотермически отожжен при температуре, превышающей $T_{\mathrm{m}}$ на $490 \mathrm{~K}$, охлажден ниже температуры кристаллизации и снова расплавлен. На основании этих результатов авторы пришли к выводу, что основным фактором, контролирующим СГП этого сплава, является температура нагрева жидкого металла над ликвидусом.

Кроме того, наблюдалось влияние структуры исходной лигатуры на способность расплава к глубокому переохлаждению. Использование гранул диаметром 3 мм в качестве шихты приводило к существенному уменьшению температуры нагрева расплава, требуемого для повышения его СГП. Например, низкотемпературная граница СГП для сплава 1 снижалась на $180 \mathrm{~K}$ (рис. 14). Аналогичный эффект был обнаружен после шихтовки сплава 2 гранулами диаметром 0.3 мм. Этот расплав становится предрасположенным к глубокому переохлаждению после нагрева на 150 К выше ликвидуса. При повышении указанной температуры до 200-400 К его склонность к глубокому переохлаждению уменьшается, но при более высоком перегреве расплава она снова воз- 
растает. СГП сплава 1 увеличивается при использовании гранул размером 0.3 мм, вместо 3-миллиметровых гранул.

Используя режимы, обеспечивающие глубокое переохлаждение расплава, в работах $[27,38]$ методом его спиннингования, были получены “толстые" аморфные ленты толщиной 70, 60 и 40 мкм (вместо обычных 20-25 мкм) из сплавов 1, 2 и 3, соответственно. Кроме того, для сплава 3 наблюдалась выраженная корреляция между способностью расплава к глубокому переохлаждению и стабильностью процесса литья лент: процесс становился стабильным только после перегрева расплава, обеспечивающего его глубокое переохлаждение. Использование гранул в качестве исходной шихты привело к увеличению толщины и улучшению качества полученных лент по сравнению с теми, которые были приготовлены по обычной технологии для сплавов с аналогичным составом. Попытки получения толстых аморфных слоев сплавов на основе железа и кобальта методом струйного литья с более высоким нагревом над ликвидусом (500-600 K) не увенчались успехом.

Позднее существенное влияние температуры закалки расплава на стеклообразование и кристаллизацию массивного металлического стекла $\mathrm{Fe}_{61} \mathrm{Co}_{7} \mathrm{Zr}_{10} \mathrm{Mo}_{5} \mathrm{~W}_{2} \mathrm{~B}_{15}$ было отмечено в [39]. В [40] показано, что температура закалки равновесного расплава $\mathrm{Fe}_{61.4} \mathrm{Ni}_{3.6} \mathrm{Cr}_{3.2} \mathrm{Si}_{2.4} \mathrm{Nb}_{7.8} \mathrm{Mn}_{3.6} \mathrm{~B}_{18}$ оказывает определяющее влияние на структуру и свойства быстро закаленных литых стержней, причем способность этого сплава к объемной аморфизации проявляется в очень узком интервале температур закалки, который близок к температурной области аномального изменения плотности исходного расплава при его охлаждении.

Пытаясь выяснить природу выявленного в работах $[27,38]$ температурного интервала нагрева расплава, который приводит к повышению его СГП, для сплава 1 измерили температурные зависимости вязкости $v$ и магнитной восприимчивости $\chi$ в жидком состоянии. Было установлено, что при первом нагревании после плавления образца скорость снижения вязкости с ростом температуры уменьшается именно в температурном диапазоне, соответствующем легкому переохлаждению. В том же диапазоне энергия активации вязкого течения в три раза ниже по сравнению с ее начальным значением. Этот эффект соответствует значительному преобразованию основных структурных составляющих течения расплава. Кривая магнитной восприимчивости в температурном диапазоне СГП не имеет аномалий. Логично предположить, что локальный порядок в данном интервале температур существенно не изменяется. Необратимые изменения магнитной восприимчивости, вероятно, связанные с трансформацией локального порядка, были обнаружены после нагрева расплава выше $1830 \mathrm{~K}$, то есть выше верхнего предела интервала легкого переохлаждения.

Результаты работ $[27,38]$ были подтверждены авторами [41, 42], которые исследовали стеклообразующую способность, вязкость в жидком состоянии, фазовый состав и микротвердость объемно аморфизирующегося сплава $\mathrm{Ni}_{64.4} \mathrm{Fe}_{4} \mathrm{Cr}_{4.9} \mathrm{Mn}_{2} \mathrm{~B}_{16.2} \mathrm{Co}_{0.5} \mathrm{Si}_{8}$, закаленного от различных температур с околокритическими скоростями. Они обнаружили, что температура закалки, обеспечивающая наиболее высокую его стеклообразующую способность, лежит в интервале 1470-1500 К и именно вблизи этой температуры имеются особенности в поведении вязкости расплава. При нагреве на зависимости вязкости от температуры зафиксирован максимум при $1520 \mathrm{~K}$, который при последующем охлаждении смещается к $1460 \mathrm{~K}$. Отмечено влияние повторных переплавов на указанные температуры, т.е. их зависимость от предыстории расплава. Позднее эти данные были дополнены сообщением о сложных зависимостях вязкости от времени в ходе изотермических выдержек расплава вблизи этих температур [43].

Мы полагаем, что после плавления расплавы данного типа являются микрогетерогенными и содержат микрочастицы, обогащенные различными элементами и взвешенные в дисперсионной среде иного состава. Внутри диапазона аномального изменения вязкости происходит некоторое изменение масштаба микрогетерогенности, 
после чего склонность расплава к глубокому переохлаждению повышается. Перегрев до более высоких температур сопровождается последовательным растворением микрочастиц различного состава и завершается переходом микрогетерогенного расплава в состояние истинного раствора. Согласно данным о склонности к глубокому переохлаждению, гомогенизированный расплав затвердевает при минимальном переохлаждении и не может быть аморфизирован при технологически достижимых скоростях охлаждения.

\section{ЗАКЛЮЧЕНИЕ}

Приведенные результаты свидетельствуют о значимости термической обработки расплавов для стабилизации служебных свойств перспективных жидкометаллических теплоносителей, для улучшения структуры и повышения эксплуатационных свойств аморфных быстро закаленных лент, а также для получения объемно аморфных слитков повышенных размеров. Сложность составов аморфных лент и слитков не позволяет дать однозначную картину изменений строения жидких прекурсоров в ходе такой обработки. Однако в результате натурных экспериментов с этими сплавами удается найти температурные интервалы указанных перестроек и использовать их с заданной целью.

\section{СПИСОК ЛИТЕРАТУРЫ}

1. Баум Б.А., Хасин Г.А., Тягунов Г.В. Жидкая сталь. М.: Металлургия, 1984.

2. Тягунов Г.В., Барышев Е.Е., Цепелев В.С. и др. Металлические жидкости. Стали и сплавы. Екатеринбург: УрФУ, 2016.

3. Popel P.S., Chikova O.A., Matveev V.M. Metastable colloidal states of liquid metallic solutions// High. Temp. Mater. Proc. 1995. 4. № 4. P. 219-233.

4. Dahlborg U., Calvo-Dahlborg M., Popel P.S., Sidorov V.E. Structure and properties of some glassforming liquid alloys// Eur. Phys. J. B. 2000. 14. P. 639-648.

5. Brodova I.G., Popel P.S., Eskin G.I. Liquid metal processing: application to aluminium alloy production. Taylor\&Francis, London and New York. 2001.

6. Субботин В.И., Арнольдов М.Н., Козлов Ф.А., Шимкевич А.Л. Жидкометаллические теплоносители для ядерной энергетики// Атомная энергия. 2002. 92. № 1. С. 31-42.

7. Попель П.С., Борисенко А.В., Гузачев М.А. и др. Эффект металлургической наследственности в жидкометаллических теплоносителях АЭС // Металлургия машиностроения. 2013. № 3. C. 009-013.

8. Гузачев М.А., Константинова Н.Ю., Попель П.С., Мозговой А.Г. Температурные зависимости кинематической вязкости жидких висмута, свинца и их взаимных растворов // Теплофизика и аэромеханика. 2011. 18б. № 3. С. 485-491.

9. Попель П.С., Замятин В.М., Домашников Б.П. и др. Влияние скандия на свойства жидкого алюминия // Изв. АН СССР. Металлы. 1983. № 3. С. 38-43.

10. Duhaj P., Sládek V., Mrafko P, Svec P. Electron microscopic study of the crystallization kinetics of the amorphous alloy $\mathrm{Pd}_{80} \mathrm{Si}_{20} / /$ J. Non-Crystalline Solids. 1974. 13. № 2. P. 341-354.

11. Cser L., Kovacs I., Lovas A. Small-angle neutron scattering study of $\mathrm{Fe}-\mathrm{B}$ and $\mathrm{Fe}-\mathrm{Ni}-\mathrm{B}$ metallic glasses // Nucl. Instrum. and Meth. Phys. Rev. 1982. 199. № 1, 2. P. 301-305.

12. Granasy L., Lovas A., Remeny T. The influence of thermal history on the physical properties of Fe-B metallic glasses // Conf. Met. Glassi Sci. and Technol. Budapest. 1981. 1. P. 197-202.

13. Либерман X.X. Приготовление образцов: различные методы и описание способов закалки из расплава / Аморфные металлические сплавы. М.: Металлургия, 1987.

14. G.E. Abrosimova, A.S. Aronin, S.P. Pankratov, A.V. Serebrjakov. Specific features of amorphous $\mathrm{Fe}_{85} \mathrm{~B}_{15}$ alloy crystallization prepared by melt quenching from different temperatures // Scr. Metall. 1980. 14. P. 967-969.

15. Novak L., Potocky L., Lovas A. Influence of melt overheating and cooling rate on magnetic properties of Fe amorphous alloys // J. Magn. And Magnetic Materials. 1980. 19. № 1. P. 149-151.

16. Попель П.С., Архангельский Е.Л., Макеев В.В. Плотность расплавов железо-бор // Высокотемпературные расплавы. 1995. 1. № 1. Р. 85-90.

17. Манов В.П., Попель С.И., Булер П.И. Влияние состояния расплава на структурно-чувствительные свойства аморфных сплавов $\mathrm{Fe}-\mathrm{B}$ и $\mathrm{Pd}-\mathrm{Si} / /$ Расплавы. 1989. № 1. P. 23-27. 
18. Manov V.P., Rubstein A., Voronel A. Effect of melt temperature on the electrical resistivity and crystallization temperature of $\mathrm{Al}_{91} \mathrm{La}_{5} \mathrm{Ni}_{4}$ and $\mathrm{Al}_{91} \mathrm{Ce}_{5} \mathrm{Ni}_{4}$ amorphous alloys // Mater. Sci. Eng. A. 1994. 179/180. P. 91-96.

19. Higashi K., Mukai T., Tanimura S. et al. Activation energy for superplastic flow in aluminum matrix composites exhibiting high strain-rate superplasticity // Scr. Mater. 1996. 34. P. 1893-1897.

20. Inoue A., Ohtera K., Tsai A.-P., Masumoto T. Aluminum-based amorphous alloys with tensile strength above $980 \mathrm{MPa}\left(100 \mathrm{~kg} / \mathrm{mm}^{2}\right) / /$ Jap. J. Appl. Phys. 1988. 27. № 4. P. L479-L482.

21. Dahlborg U., Calvo-Dahlborg M. Influence of the production conditions on the structure and microstructure of metallic glasses. International Workshop "Mechanical Properties of Metallic Glasses", Kosice, Slovakia. 1998. P. 17-27.

22. Dahlborg U., Calvo-Dahlborg M. Influence of the production conditions on the structure and the microstructure of metallic glasses studied by neutron scattering // Mater. Sci. Eng. A. 2000. 283. P. 153-163.

23. Calvo M. Application of the Weibull statistics to the characterization of metallic glass Ribbons // J. Mater. Sci. 1989. 24. P. 1801-1808.

24. Bengus V.Z., Tabachnikova E.D., Duhaj P., Ocelik V. Low temperature mechanical properties of metallic glasses connection with structure // Mater. Sci. Eng. A. 1997. 226-228. P. 823-832.

25. Tabachnikova E.D., Bengus V.Z., Egorov D.V. Mechanical properties of amorphous alloys ribbons prepared by rapid quenching of the melt after different thermal treatment before quenching // Mater. Sci. Eng. A. 1997. 226-228. P. 887-890.

26. Sidorov V., Popel P., Calvo-Dahlborg M. et al. Heat treatment of iron based melts before quenching // Mater. Sci. Eng. A. 2001. 304. P. 480-486.

27. Manov V., Popel P.S., Brook-Levinson E. Influence of the thermal treatment of melt on the properties of amorphous materials: ribbons, bulks and glass coated microwires // Mater. Sci. Eng. A. 2001. 304. P. 54-60.

28. Sidorov V.E., Calvo-Dahlborg M., Dahlborg U. Physical properties of some iron based alloys in liquid and amorphous states // J. Mat. Sci. 2000. 35. P. 2255-2262.

29. Calvo-Dahlborg M., Ruppert J.M., Tabachnikova E.D. Influence of the melt on the structure and mechanical behavior of metallic glass ribbons // Journal de Physique (France). 2001. 11. P. 4-49.

30. A. Inoue. Stabilization of metallic supercooled liquid and bulk amorphous alloys // Acta mater. 2000. 48. P. 279-306.

31. V.V. Molokanov, V.N. Chebotnikov. Glass forming ability, structure and properties of Ti- and Zrintermetallic compound based alloys // Key Eng. Mater. 1990. 40-41. P. 319-332.

32. М. Петржик, В. Молоканов, Т. Михайлова. Влияние третьего компонента на стеклообразующую способность сплавов Ni-Мо // Известия АН СССР. Металлы. 1996. № 4. С. 151-154.

33. D.M. Herlach, Solidification from undercooled melt // Mater. Sci. Eng. A. 1997. 226-228. P. 348-356.

34. M. Schwartz, A. Karma, K. Eckler, D.M. Herlach, Physical mechanism of grain refinement in solidification of undercooled melt // Phys. Rev. Lett. 1994. 73. № 10. P. 1380-1383.

35. R. Willnecker, D.M. Herlach, B. Feurbacher, Grain refinement induced by a critical crystal growth velocity in undercooled melts // Appl. Phys. Lett. 1990. 56. № 4. P. 324-326.

36. X.H. Lin, W.L. Johnson, W.K. Rhim. Effect of oxygen impurity on crystallization of an undercooled bulk glass forming $\mathrm{Zr}-\mathrm{Ti}-\mathrm{Cu}-\mathrm{Ni}-\mathrm{Al}$ alloy // Mat. Trans. JIM. 1997. 38. № 5. P. 473-477.

37. L.Q. Xing, P. Ochin. Bulk glass formation in the $\mathrm{Zr}-\mathrm{Ti}-\mathrm{Al}-\mathrm{Cu}-\mathrm{Ni}$ system // J. Mat. Sci. Lett. 1997. 16. P. 1277-1280.

38. Молоканов В.В., Петржик М.И., Михайлова Е.Н. Влияние термической обработки расплава на свойства и стеклообразуюшую способность магнитомягкого сплава $\mathrm{Fe}_{76.8} \mathrm{Ni}_{1.3} \mathrm{Si}_{8.6} \mathrm{~B}_{13.5} / /$ Расплавы. 2000. № 4. С. 40-48.

39. Молоканов В.В., Петржик М.И., Филиппов К.С. и др. Влияние температуры закалки расплава на стеклообразование и кристаллизацию массивного металлического стекла $\mathrm{Fe}_{61} \mathrm{Co}_{7} \mathrm{Zr}_{10} \mathrm{Mo}_{5} \mathrm{~W}_{2} \mathrm{~B}_{15} / /$ Материаловедение. 2002. № 1. С. 42-45.

40. Молоканов В.В., Шалыгин А.Н., Петржик М.И. и др. Влияние состояния расплава на стеклообразующую способность, структуру и свойства быстрозакаленных литых стержней объемного аморфного сплава на основе железа // Перспективные материалы. 2003. № 3. С. 10-16.

41. Стерхова И.В., Камаева Л.В., Ладьянов В.И. О вязкости объемно-аморфизуемого расплава // Вестник Удмуртского университета. Физика. 2007. № 4. С. 77-82.

42. Куракова Н.В., Молоканов В.В., Стерхова И.В. и др. Влияние состояния расплава на стеклообразующую способность, структуру и свойства быстрозакаленного аморфного сплава на основе никеля // Известия РАН. Металлы. 2007. № 6б. С. 89-93.

43. Lad'janov V.I., Sterkhova I.V., Kamaeva L.I. On the solidification of the $\mathrm{Fe}_{50} \mathrm{Cr}_{15} \mathrm{Mo}_{14} \mathrm{C}_{15} \mathrm{~B}_{6}$ bulkamorphized alloy // J. Non-Crystalline Solids. 2010. 356. P. 65-71. 


\title{
THE INFLUENCE OF THERMAL TREATMENT OF LIQUID ALLOY ON ITS PROPERTIES IN MELTED STATE AND AFTER THE CRYSTALLIZATION
}

\author{
P. S. Popel ${ }^{1}$, V. E. Sidorov' ${ }^{1}$, M. Calvo-Dahlborg' ${ }^{2}$, U. Dahlborg'2 , V. V. Molokanov ${ }^{3}$ \\ ${ }^{1}$ Ural State Pedagogical University, Yekaterinburg, Russia \\ ${ }^{2}$ University of Rouen, Rouen, France \\ ${ }^{3}$ Bajkov's Institute of Metallurgy and Material Science RAS, Moscow, Russia
}

\begin{abstract}
The idea of using optimized heat treatment of initial melts in order to stabilize the properties of promising liquid metal coolants in nuclear reactors is formulated basing on the previously published statements about the possibility of regulating the structure of liquid alloys by varying their temperature. This idea is confirmed by the results for liquid binary eutectics leadbismuth, lead-tin and gallium-indium. The evidences for their metastable microheterogeneous structure in the wide temperature ranges and for a long time after the coolants melting were obtained experimentally. It was shown that the variations in melt preparation do not affect significantly the degree of its heterogeneity and the temperature of transition to a homogeneous state. The main ways to eliminate the influence of the indicated microheterogeneity on the safety of the reactor are determined. The possibility of improving the quality of amorphous ribbons obtained by rapid quenching and bulk amorphous alloysulation by optimization of smelting temperature regimes is discussed. The effect of melt heat treatment on structure and properties of amorphous samples obtained by the standard spinning method is shown using several examples. It has been established that overheating of liquid metal above the metastable microheterogeneous area promotes the formation of a more disordered amorphous structure compared with the standard smelting technology and thus allows one to expand significantly the concentration range of alloy amorphization. The efficiency of heating a microheterogeneous melt to temperatures of its intermediate structural rearrangements between two microheterogeneous states is shown and confirmed not only in laboratory experiments, but in industrial full-scale production of amorphous ribbons also. To understand the reasons for the formation of bulk amorphous alloys, the relation between heating temperature and melts tendency to deep supercooling is of key importance. It was found that there is a specific temperature range where the melt becomes prone to deep supercooling, and its rate of viscosity decrease with increasing temperature and the activation energy of the viscous flow are reduced significantly. The reasons for such a correlation are discussed.
\end{abstract}

Keywords: melts, optimized heat treatment, liquid metal coolants, quenching rate, amorphous ribbons and bulk amorphous alloys, structure, properties

\section{REFERENCES}

1. Baum B.A., Khasin G.A., Tjagunov G.V. Zhidkaja stal' [Liquid steel]. M.: Metallurgija Publ. 1984. (in Russian).

2. Tjagunov G.V., Baryshev E.E., Tsepelev V.S. et al. Metallicheskije zhidkosti. Stali i splavy [Metallic Liquids. Steels and alloys]; Yekaterinburg: UrFU. 2016. (in Russian).

3. Popel P.S., Chikova O.A., Matveev V.M. Metastable colloidal states of liquid metallic solutions// High. Temp. Mater. Proc. 1995. 4. № 4. P. 219-233.

4. Dahlborg U., Calvo-Dahlborg M., Popel P.S., Sidorov V.E. Structure and properties of some glassforming liquid alloys// Eur. Phys. J. B. 2000. 14. P. 639-648.

5. Brodova I.G., Popel P.S., Eskin G.I. Liquid metal processing: application to aluminium alloy production. Taylor\&Francis, London and New York. 2001.

6. Subbotin V.I., Arnol'dov M.N., Kozlov F.A., Shimkjevich A.L. Zhidkometallicheskije teplonociteli dlja jadernoj energetiki [Liquid metal heat carriers for nuclear energetics] // Atomnaja energija. 2002. 92. № 1. P. 31-42. (in Russian).

7. Popel P.S., Borisenko A.V., Guzachev M.A. et al. Effekt metallurgicheskoj nasledstvennosti v zhidkometallicheskikh teplonositeljakh AES [Effect of metallurgical heredity in liquid metal heat carriers of NPP] // Metallurgija mashinostrojenija. 2013. № 3. P. 009-013. (in Russian).

8. Guzachev M.A., Konstantinova N.Ju., Popel P.S., Mozgovoj A.G. Temperaturnyje zavisimosti kinematicheskoj vjazkosti zhidkikh vismuta, svintsa i ikh vzaimnykh rastvorov [Temperature dependences of kinematic viscosity of liquid bismuth, lead and their mutual solutions] // Teplofizika I aeromekhanika. 2011. 18б. № 3. P. 485-491. (in Russian). 
9. Popel P.S., Zamjatin V.M., Domashnikov B.P. et al. Vlijanije skandija na svojstva zhidkogo aluminija [The influence of scandium on properties of liquid aluminum] // Izv. AN SSSR. Metally. 1983. № 3. P. 38-43. (in Russian).

10. Duhaj P., Sládek V., Mrafko P, Svec P. Electron microscopic study of the crystallization kinetics of the amorphous alloy $\mathrm{Pd}_{80} \mathrm{Si}_{20} / /$ J. Non-Crystalline Solids. 1974. 13. № 2. P. 341-354.

11. Cser L., Kovacs I., Lovas A. Small-angle neutron scattering study of $\mathrm{Fe}-\mathrm{B}$ and $\mathrm{Fe}-\mathrm{Ni}-\mathrm{B}$ metallic glasses // Nucl. Instrum. and Meth. Phys. Rev. 1982. 199. № 1, 2. P. 301-305.

12. Granasy L., Lovas A., Remeny T. The influence of thermal history on the physical properties of $\mathrm{Fe}-\mathrm{B}$ metallic glasses // Conf. Met. Glassi Sci. and Technol. Budapest. 1981. 1. P. 197-202.

13. Liberman H.H. Prigotovlenije obraztsov: razlichnyje metody i opisanije sposobov zakalki iz rasplava [Samples preparation: various methods and description of quenching from melts methods] Luborsky F.E. ed. Translation from English. M.: Metallurgija, 1987. (in Russian).

14. Abrosimova G.E., Aronin A.S., Pankratov S.P., Serebrjakov A.V. Specific features of amorphous $\mathrm{Fe}_{85} \mathrm{~B}_{15}$ alloy crystallization prepared by melt quenching from different temperatures // Scr. Metall. 1980. 14. P. 967-969.

15. Novak L., Potocky L., Lovas A. Influence of melt overheating and cooling rate on magnetic properties of Fe amorphous alloys // J. Magn. And Magnetic Materials. 1980. 19. № 1. P. 149-151.

16. Popel P.S., Arkhangelsky E.L., Makejev V.V. Plotnost rasplavov zhelezo-bor [Density of iron-boron melts] // Vysokotemperaturnyje rasplavy. 1995. 1. № 1. P. 85-90. (in Russian).

17. Manov V.P., Popel S.I., Buler P.I. Vlijanije sostojanija rasplava na structurno-chuvstvitel'nyje svojstva amorphnykh splavov $\mathrm{Fe}-\mathrm{B}$ i $\mathrm{Pd}-\mathrm{Si}$ [The influence of melt state on the properties of amorphous alloys $\mathrm{Fe}-\mathrm{B}$ and $\mathrm{Pd}-\mathrm{Si}$ sensitive to their structure] // Rasplavy. 1989. № 1. P. 23-27. (in Russian).

18. Manov V.P., Rubstein A., Voronel A. Effect of melt temperature on the electrical resistivity and crystallization temperature of $\mathrm{Al}_{91} \mathrm{La}_{5} \mathrm{Ni}_{4}$ and $\mathrm{Al}_{91} \mathrm{Ce}_{5} \mathrm{Ni}_{4}$ amorphous alloys // Mater. Sci. Eng. A. 1994. 179/180. P. 91-96.

19. Higashi K., Mukai T., Tanimura S. et al. Activation energy for superplastic flow in aluminum matrix composites exhibiting high strain-rate superplasticity // Scr. Mater. 1996. 34. P. 1893-1897.

20 Inoue A., Ohtera K., Tsai A.-P., Masumoto T. Aluminum-based amorphous alloys with tensile strength above $980 \mathrm{MPa}(100 \mathrm{~kg} / \mathrm{mm} 2) / /$ Jap. J. Appl. Phys. 1988. 27. № 4. P. L479-L482.

21. Dahlborg U., Calvo-Dahlborg M. Influence of the production conditions on the structure and microstructure of metallic glasses. International Workshop "Mechanical Properties of Metallic Glasses”, Kosice, Slovakia. 1998. P. 17-27.

22. Dahlborg U., Calvo-Dahlborg M. Influence of the production conditions on the structure and the microstructure of metallic glasses studied by neutron scattering // Mater. Sci. Eng. A. 2000. 283. P. $153-163$.

23. Calvo M. Application of the Weibull statistics to the characterization of metallic glass Ribbons // J. Mater. Sci. 1989. 24. P. 1801-1808.

24. Bengus V.Z., Tabachnikova E.D., Duhaj P., Ocelik V. Low temperature mechanical properties of metallic glasses connection with structure // Mater. Sci. Eng. A. 1997. 226-228. P. 823-832.

25. Tabachnikova E.D., Bengus V.Z., Egorov D.V. Mechanical properties of amorphous alloys ribbons prepared by rapid quenching of the melt after different thermal treatment before quenching // Mater. Sci. Eng. A. 1997. 226-228. P. 887-890.

26. Sidorov V., Popel P., Calvo-Dahlborg M. et al. Heat treatment of iron based melts before quenching // Mater. Sci. Eng. A. 2001. 304. P. 480-486.

27. Manov V., Popel P.S., Brook-Levinson E. Influence of the thermal treatment of melt on the properties of amorphous materials: ribbons, bulks and glass coated microwires // Mater. Sci. Eng. A. 2001. 304. P. 54-60.

28. Sidorov V.E., Calvo-Dahlborg M., Dahlborg U. Physical properties of some iron based alloys in liquid and amorphous states // J. Mat. Sci. 2000. 35. P. 2255-2262.

29. Calvo-Dahlborg M., Ruppert J.M., Tabachnikova E.D. Influence of the melt on the structure and mechanical behavior of metallic glass ribbons // J. Physique (France). 2001. 11. P. 4-49.

30. A. Inoue. Stabilization of metallic supercooled liquid and bulk amorphous alloys // Acta mater. 2000. 48. P. 279-306.

31. V.V. Molokanov, V.N. Chebotnikov. Glass forming ability, structure and properties of Ti- and Zrintermetallic compound based alloys // Key Eng. Mater. 1990. 40-41. P. 319-332.

32. Petrzhik M., Molokanov V., Mikhajlova T. Vlijanije tretjego komponenta na stekloobrazujusthuju sposobnost' splavov Ni-Mo [The influence of the third component on the glass forming ability of Ni-Mo alloys] // Izvestija AN SSSR. Metally. 1996. № 4. P. 151-154. (in Russian).

33. Herlach D.M. Solidification from undercooled melt // Mater. Sci. Eng. A. 1997. 226-228. P. 348356.

34. Schwartz M., Karma A., Eckler K., Herlach D.M. Physical mechanism of grain refinement in solidification of undercooled melt // Phys. Rev. Lett. 1994. 73. № 10. P. 1380-1383.

35. Willnecker R., Herlach D.M., Feurbacher B. Grain refinement induced by a critical crystal growth velocity in undercooled melts // Appl. Phys. Lett. 1990. 56. № 4. P. 324-326. 
36. Lin X.H., Johnson W.L., Rhim W.K. Effect of oxygen impurity on crystallization of an undercooled bulk glass forming $\mathrm{Zr}-\mathrm{Ti}-\mathrm{Cu}-\mathrm{Ni}-\mathrm{Al}$ alloy // Mat. Trans. JIM. 1997. 38. № 5. P. 473-477.

37. Xing L.Q., Ochin P. Bulk glass formation in the $\mathrm{Zr}-\mathrm{Ti}-\mathrm{Al}-\mathrm{Cu}-\mathrm{Ni}$ system // J. Mat. Sci. Lett. 1997. 16. P. $1277-1280$.

38. Molokanov V.V., Petrzhik M.I., Mikhajlova E.N. Vlijanije termicheskoj obrabotki rasplava na svojstva I stekloobrazujustchuju sposobnost' magnitomjagkogo splava $\mathrm{Fe}_{76.8} \mathrm{Ni}_{1.3} \mathrm{Si}_{8.6} \mathrm{~B}_{13.5}$ [The influence of thermal treatment of melt on properties and glass forming ability of the soft magnetic alloy $\mathrm{Fe}_{76.8} \mathrm{Ni}_{1.3} \mathrm{Si}_{8.6} \mathrm{~B}_{13.5}$ / // Rasplavy. 2000. № 4. P. 40-48. (in Russian).

39. Molokanov V.V., Petrzhik M.I., Filippov K.S. Vlijanije temperatury zakalki rasplava na stekloobrazovanije I kristallizaciju massivnogo metallicheskogo stekla $\mathrm{Fe}_{61} \mathrm{Co}_{7} \mathrm{Zr}_{10} \mathrm{Mo}_{5} \mathrm{~W}_{2} \mathrm{~B}_{15}$ [The influence of melt quenching temperature on glass formation and crystallization of massive metallic glass $\left.\mathrm{Fe}_{61} \mathrm{Co}_{7} \mathrm{Zr}_{10} \mathrm{Mo}_{5} \mathrm{~W}_{2} \mathrm{~B}_{15}\right] / /$ Materialovedenije. 2002. № 1. P. 42-45. (in Russian).

40. Molokanov V.V., Shalygin A.N., Petrzhik M.I. Vlijanije sostojanija rasplava na stekloobrazujustchuju sposobnost', strukturu I svojstva bystrozakalennykh litykh sterzhnej objemnogo amorfnogo splava na osnove zheleza [The influence of state of the melt on glass forming ability, structure and properties of rapidly quenched cast rods of the iron based bulk amorphous alloy] // Perspektivnyje materialy. 2003. № 3. P. 10-16. (in Russian).

41. Sterkhova I.V., Kamajeva L.V., Ladjanov V.I. O vjazkosty objomno amorfnogo splava [About viscosity of bulk amorphous melt] // Vestnik Udmurtskogo universiteta. Fizika. 2007. № 4. P. 77-82. (in Russian).

42. Kurakova N.V., Molokanov V.V., Sterkhova I.V. Vlijanije sostojanija rasplava na stekloobrazujustchuju sposobnost', strukturu I svojstva bystrozakaljonnogo amorfnogo splava na osnove nikelja [The influence of state of the melt on the glass forming ability, structure and properties of the rapidly quenched amorphous nickel-based alloy] // Izvestija RAN. Metally. 2007. № 66. P. 89-93. (in Russian).

43. Lad'janov V.I., Sterkhova I.V., Kamaeva L.I. On the solidification of the $\mathrm{Fe}_{50} \mathrm{Cr}_{15} \mathrm{Mo}_{14} \mathrm{C}_{15} \mathrm{~B}_{6}$ bulkamorphized alloy // J. Non-Crystalline Solids. 2010. 356. P. 65-71. 